\title{
Cross-sectional Study on Utilization of Radiology and Imaging Equipment in the District Hospitals of Bangladesh
}

\author{
${ }^{1}$ Md Mofazzal Hossain, ${ }^{2}$ Papia Sultana, ${ }^{3} \mathrm{M}$ Shahjahan
}

\begin{abstract}
A quality diagnosis mostly depends on the availability and proper utilization of radiology and imaging equipments in the modern medical technology. Every year, huge amount of revenue is spent to purchase costly and sophisticated radiology and imaging equipments for the district hospitals of Bangladesh. But radiology and imaging equipments are underutilized in most of the developing Asian and African countries, including Bangladesh. This descriptive cross-sectional study was conducted to find the functional status, workload, utilization, and factors affecting the utilization of radiology and imaging equipments in the district hospitals of Bangladesh. Interviewer-administered questionnaire was used to take interview of relevant human resources. Work time study method was applied where multiple checklists were used to measure consumed time for each procedure and daily actual work time of radiology and imaging equipments. In this study, 46.9\% radiology and imaging equipments were found functional, $40.6 \%$ radiology and imaging equipments nonfunctional, and $12.5 \%$ radiology and imaging equipments functional but not in use. This study revealed that $53 \%$ of total radiology and imaging equipments of district hospitals were nonfunctional, and functional but not in use, where 8 equipments became nonfunctional before 10 years due to unavailability of spare parts and inadequate maintenance fund. Work time in radiography identified $83.51 \%$ and in ultrasonography (USG) $71.08 \%$ among the respondents of radiology and imaging department in the district hospitals. Utilization rate of general radiography equipments was found to be $67.01 \%$, portable radiography equipments $16.5 \%$, and USG equipments $71.08 \%$. Average utilization rate of radiology and imaging equipments was found to be $51.53 \%$ in the district hospitals of Bangladesh. Utilization rate of radiology and imaging equipments more than $50 \%$ is considered as standard utilization. Current status of utilization rate needs to accelerate to get maximum turnover of the equipments among the district hospitals of Bangladesh. Important factors affecting the utilization of radiology and imaging equipments were observed - shortage of manpower, inadequate physical infrastructure, and less incorporation of advanced technology with existing facility.
\end{abstract}

\footnotetext{
${ }^{1}$ Senior Medical Technologist, ${ }^{2}$ Lecturer, ${ }^{3}$ Professor

${ }^{1}$ Department of Radiology, International Centre for Diarrhoeal Disease Research of Bangladesh, Dhaka, Bangladesh

${ }^{2}$ Department of Public Health, State University of Bangladesh Dhaka, Bangladesh

${ }^{3}$ Department of Public Health Administration \& Hospital Management, State University of Bangladesh, Dhaka, Bangladesh

Corresponding Author: Md Mofazzal Hossain, Senior Medical Technologist, Department of Radiology, International Centre for Diarrhoeal Diseases Research of Bangladesh, Dhaka Bangladesh, Phone: 8801710960825, e-mail:mhrt@icddrb.org
}

Keywords: District hospital, Functional status, Radiology and imaging equipments, Utilization, Workload.

How to cite this article: Hossain MM, Sultana P, Shahjahan M. Cross-sectional Study on Utilization of Radiology and Imaging Equipment in the District Hospitals of Bangladesh. Int J Res Foundation Hosp Healthc Adm 2017;5(1):21-28.

\section{Source of support: Nil}

Conflict of interest: None

\section{INTRODUCTION}

Radiology and imaging play a vital role in modern medical science, so that medical imaging is considered as the heart of medical practice. It is almost impossible to appropriately diagnose and medicate most health conditions without the use of radiology and imaging equipment. It is one of the most rapid changing technologies in modern medical science. According to studies in India, United States, European Union, Norway, and Ethiopia, spare parts of old equipment become unavailable after a certain period due to rapid technological development and changing modalities. It becomes mostly impossible to maintain the continuous utilization of the existing defective or malfunctioning radiology and imaging equipment. ${ }^{1-5}$

According to Bangladesh Medical Equipment Survey Report 2008 and World Health Organization report on Human Resources for Health, Bangladesh has a severe shortage of allied health professionals mostly in Upazila Health Complex and district hospitals. Many of the hospitals have not adequate manpower to operate the equipments, and a remarkable number of equipments lose their half-life before installation due to inadequate physical infrastructure. Electromedical equipments are not maintained properly due to unavailable biomedical engineer, unavailable maintenance services and spare parts. Follow-through productivity of radiology and imaging equipments becomes poor and finally the utilization of radiology and imaging equipments becomes unsatisfactory within its lifetime. Every year, a lot of revenue is being wasted to operate the lower productive equipment in the district hospitals of Bangladesh. ${ }^{5-7}$

According to Health Facility Survey Report 2014, every year 40 to $50 \%$ of total budget of health sector is spent to purchase the medical equipments. ${ }^{5,6}$ Radiology and imaging equipment is also costly and sophisticated, so that every year a large amount of revenue is spent to 
purchase the equipments. But the productivity of these costly equipments depends upon proper utilization. Lower utilization denotes higher cost of health care facilities and higher utilization improves the productivity of the equipment, so that health care cost becomes lower and affordable. Improper and inadequate utilization of medical equipment is increasing among many countries of the world. Most of the poor utilizing countries are also situated in South-east Asia and Africa along with Bangladesh. Thus, the objectives of the study were to identify functional status, workload, utilization, as well as factors affecting the utilization of radiology and imaging equipments in the district hospitals of Bangladesh.

\section{MATERIALS AND METHODS}

A cross-sectional descriptive study was conducted in three district hospitals of Bangladesh from September 1 to December 30, 2016. The purposively selected three district hospitals were District General Hospital, Gajipur, District General Hospital, Shirajgonj, and 250-bedded District Shadar Hospital, Kishorgonj. In this study, the respondents were authorized radiology and imaging equipments and relevant human resources working in the radiology department of district hospitals. Work time study method was used to measure actual work time, workload, and actual utilization of radiology and imaging equipments. Interviewer-administered questionnaire was used to take interview with nine human respondents. Different checklists were used to collect data of functional status, installation date, starting date of radiology and imaging equipments, and radiological procedures carried out from June to October 2016 from the record book of district hospitals. Utilization of 9 radiology and imaging equipments in three categories and 232 radiology and imaging procedures was observed during the study period. The quantitative data and identified factors were analyzed by using Statistical Package for the Social Sciences (SPSS) and MS Excel.

\section{RESULTS}

The study was carried out to identify the status of utilization of radiology and imaging equipments in the selected district hospitals of Bangladesh. Data were collected from the District General Hospital, Gajipur (study area 1), District General Hospital, Shirajgonj (study area 2), and 250-bedded District Shadar Hospital, Kishorgonj (study area 3). After completing data analysis, the following results were found from the study.

Table 1 shows that 32 radiological equipments were available in the three district hospitals. Among them were 7 general radiography (GR), 6 portable radiography (PR), 1 digital radiography (DR), 3 dental radiography (Dt.R), 12 ultrasonography (USG), 2 Auto-processor (AP), and 1 computed radiography (CR). These radiology and imaging equipments are authorized by the Directorate General of Health Services for district hospitals in Bangladesh but only three categories of equipments were available in the three study area. Table 1 also indicates that $15(46.9 \%)$ radiology and imaging equipments were functional, 13 (40.6\%) equipments were nonfunctional, and $4(12.5 \%)$ equipments were functional but not in use.

Table 2 shows 13 nonfunctioning radiology and imaging equipments in the three district hospitals, where 3 (23.08\%) equipments were found nonfunctioning for a long time due to unavailable service engineer of the respective vendor, 6 (46.15\%) equipments were found nonfunctioning due to unavailable spare parts, 3 (23.08\%) equipments were found nonfunctioning due to unavailable fund for repairing the equipment, 1 (7.69\%) equipment was found nonfunctioning which was donated 5 years ago and from the very beginning the equipment remained nonfunctioning.

Table 3 indicates that average of 32 (32.39) GR procedures were done in the district hospitals for which required time was 261.34 minutes, average 7 PR procedures were done for which required working time was 64.35 minutes. The study found average consumed time of 326.9 minutes for average number of 39 radiology and imaging procedures. So that actual work time of human

Table 1: Current status of radiology and imaging equipments in the three district hospitals of Bangladesh

\begin{tabular}{lllll}
\hline List of equipment & No. of FE (\%) & No. of NFE (\%) & No. of FNU (\%) & Total no. equipments (\%) \\
\hline GR & $5(15.63 \%)$ & $2(6.25 \%)$ & $0(0 \%)$ & $07(1.88 \%)$ \\
FR & $0(0 \%)$ & $0(0 \%)$ & $0(0 \%)$ & $00(0 \%)$ \\
PR & $3(9.38 \%)$ & $1(3.13 \%)$ & $2(6.25 \%)$ & $06(18.76 \%)$ \\
DR & $1(3.13 \%)$ & $0(0 \%)$ & $0(0 \%)$ & $01(3.13 \%)$ \\
Dt.R & $1(3.13 \%)$ & $0(0 \%)$ & $2(6.25 \%)$ & $03(0.38 \%)$ \\
USG & $4(12.5 \%)$ & $8(25 \%)$ & $0(0 \%)$ & $12(37.5 \%)$ \\
AP & $0(0 \%)$ & $2(6.25 \%)$ & $0(0 \%)$ & $02(6.25 \%)$ \\
CR & $1(3.13 \%)$ & $0(0 \%)$ & $0(0 \%)$ & $01(3.13 \%)$ \\
\hline Total & $15(46.9 \%)$ & $13(40.6 \%)$ & $4(12.5 \%)$ & $32(100 \%)$ \\
\hline
\end{tabular}

FE: Functional equipments; NFE: Nonfunctional equipments; FNU: Functional but not in use equipments; FR: Fluoroscopy machine; AP: Auto-processor 
Cross-sectional Study on Utilization of Radiology and Imaging Equipment in the District Hospitals of Bangladesh

Table 2: Distribution of the reasons of nonfunctioning radiology and imaging equipments

\begin{tabular}{llllll}
\hline Total & \multicolumn{5}{l}{ Reasons of NF radiology and imaging equipments } \\
\hline NFE & UME & USP & UMF & LAP & Others \\
\hline $13(100 \%)$ & $3(23.08 \%)$ & $6(46.15 \%)$ & $3(23.07 \%)$ & $1(7.69 \%)$ & $0(0 \%)$ \\
\hline
\end{tabular}

NFE: Nonfunctional equipments; UME: Unavailable maintenance engineer; USP: Unavailable spare parts; UMF: Unavailable maintenance fund; LAP: Lengthy administrative process

Table 3: Distribution of GR, PR, average radiology, and imaging procedure done/day and average consumed time in the three study areas

\begin{tabular}{|c|c|c|c|c|c|c|c|c|}
\hline \multirow[b]{2}{*}{$\begin{array}{l}\text { Type of } \\
\text { procedure }\end{array}$} & \multicolumn{2}{|c|}{ Study area 1} & \multicolumn{2}{|c|}{ Study area 2} & \multicolumn{2}{|c|}{ Study area 3} & \multirow{2}{*}{$\begin{array}{l}\text { Average } \\
\text { radiology } \\
\text { procedure } \\
\text { done/day }\end{array}$} & \multirow{2}{*}{$\begin{array}{l}\text { Average } \\
\text { consumed time } \\
\text { (minutes)/day }\end{array}$} \\
\hline & $\begin{array}{l}\text { No. of } \\
\text { procedure }\end{array}$ & $\begin{array}{l}\text { Consumed } \\
\text { time }\end{array}$ & $\begin{array}{l}\text { No. of } \\
\text { procedure }\end{array}$ & $\begin{array}{l}\text { Consumed } \\
\text { time }\end{array}$ & $\begin{array}{l}\text { No. of } \\
\text { procedure }\end{array}$ & $\begin{array}{l}\text { Consumed } \\
\text { time }\end{array}$ & & \\
\hline GR & 45 & 298.34 & 23 & 203.03 & 30 & 283.05 & 32 (32.39) & 261.34 \\
\hline PR & 6 & 45.30 & 7 & 62.03 & 9 & 86.10 & $7(7.19)$ & 64.35 \\
\hline Total & 51 & 344.04 & 30 & 265.06 & 39 & 369.15 & 39 & 326.9 \\
\hline
\end{tabular}

Table 4: Distribution of USG done/day and average consumed time/day in the three study areas

\begin{tabular}{|c|c|c|c|c|c|c|c|c|}
\hline \multirow[b]{2}{*}{$\begin{array}{l}\text { Types of } \\
\text { procedures }\end{array}$} & \multicolumn{2}{|c|}{ Study area 1} & \multicolumn{2}{|c|}{ Study area 2} & \multicolumn{2}{|c|}{ Study area 3} & \multirow{2}{*}{$\begin{array}{l}\text { Average } \\
\text { procedure } \\
\text { done/day }\end{array}$} & \multirow{2}{*}{$\begin{array}{l}\text { Average } \\
\text { consumed } \\
\text { time/day }\end{array}$} \\
\hline & $\begin{array}{l}\text { No. of } \\
\text { procedure }\end{array}$ & $\begin{array}{l}\text { Consumed } \\
\text { time }\end{array}$ & $\begin{array}{l}\text { No. of } \\
\text { procedure }\end{array}$ & $\begin{array}{l}\text { Consumed } \\
\text { time }\end{array}$ & $\begin{array}{l}\text { No. of } \\
\text { procedure }\end{array}$ & $\begin{array}{l}\text { Consumed } \\
\text { time }\end{array}$ & & \\
\hline USG & 36 & 324.03 & 25 & 180.35 & 51 & 327.40 & $37.33(38)$ & 277.26 minute \\
\hline
\end{tabular}

resource and radiography equipments identified $83.51 \%$ (326.9 minutes) and idle time $16.49 \%$ (63.51 minutes). The daily working time was considered $6 \frac{1}{2}$ hours (8:00 am to $2: 30 \mathrm{pm})$.

Table 4 shows that average 37 (37.33) USG procedures were done in the district hospitals for which required working time was 277.26 minutes. The actual work time in USG identified $71.08 \%$ (277.26 minutes) and idle time $28.92 \%$ (112.34 minutes). The daily working time was considered $6 \frac{1}{2}$ hours $(8: 00$ am to $2: 30 \mathrm{pm})$ in the district hospitals of Bangladesh.

Graph 1 illustrates daily utilization rate of GR and PR equipments in the three district hospitals of Bangladesh. In study area 1, utilization rate of GR was found to be $76.50 \%$ and PR $11.62 \%$. In study area 2 , utilization of GR

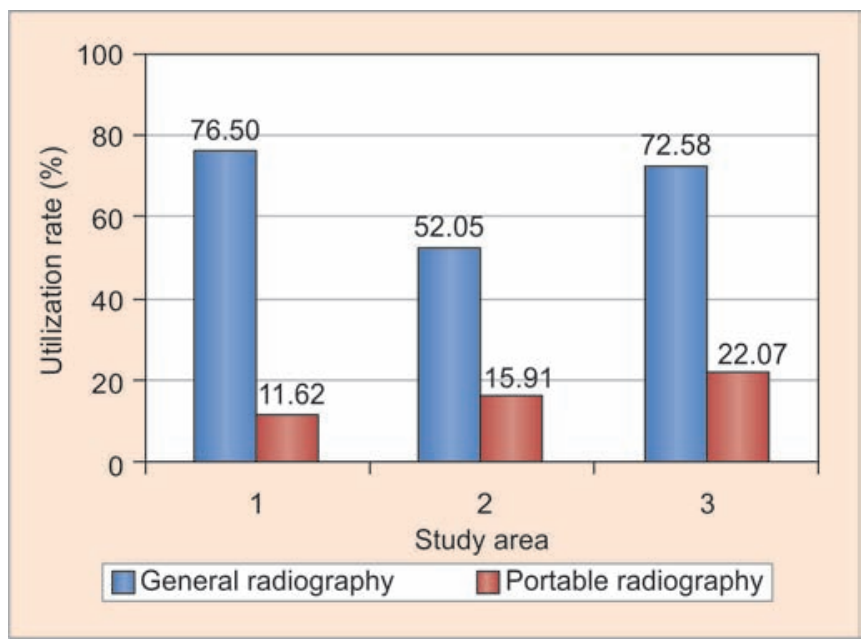

Graph 1: Distribution of daily utilization rate of GR and PR equipments in the three district hospitals was found to be $52.05 \%$ and PR $15.91 \%$. In study area 3, utilization rate of GR was found to be $72.58 \%$ and PR $22.07 \%$.

Graph 2 shows daily utilization rate of USG equipments in the three district hospitals of Bangladesh. The utilization rate was found in study area $1-83.08 \%$, study area $2-46.24 \%$, and study area $3-83.95 \%$.

Table 5 shows that average utilization rate of GR equipments $-67.01 \%$, PR equipments $-16.50 \%$, and USG equipments $-71.08 \%$. Finally, our study found the average radiology and imaging equipments utilization rate of $51.53 \%$ in the district hospitals of Bangladesh.

Graph 3 shows current status of utilization rate of radiology and imaging equipments as 52\% (51.53) and nonutilization rate of $48 \%$ (48.47) in the district hospitals of Bangladesh.



Graph 2: Distribution of daily utilization rate of USG equipments in the three district hospitals 
Table 5: Actual utilization rate of radiology and imaging equipments

\begin{tabular}{lllll}
\hline $\begin{array}{l}\text { Types of } \\
\text { equipment }\end{array}$ & $\begin{array}{l}\text { Study area } \\
1(\%)\end{array}$ & $\begin{array}{l}\text { Study area } \\
\text { 2(\%) }\end{array}$ & $\begin{array}{l}\text { Study area } \\
\text { 3 (\%) }\end{array}$ & $\begin{array}{l}\text { Average } \\
\text { REUR (\%) }\end{array}$ \\
\hline GR & 76.50 & 52.05 & 72.58 & 67.01 \\
PR & 11.62 & 15.91 & 22.07 & 16.50 \\
USG & 83.08 & 46.24 & 83.95 & 71.08 \\
Av. REUR & 57.07 & 38.07 & 59.53 & 51.53 \\
\hline
\end{tabular}

REUR: Radiology and imaging equipments utilization rate

Graph 4 shows the analysis of the perception-based factors affecting the utilization. Perceptions of $100 \%$ respondents were shortage of manpower, lack of orientation course, unavailable spare parts, and delayed maintenance services that affect the utilization of radiology and imaging equipments; perceptions of $66.66 \%$ respondents were inadequate physical infrastructure, inadequate working hours/day, insufficient radiation safety program, and others (quality of accessories, unavailable servicing fund, and lengthy administrative process) that affect the utilization; perceptions of $33.34 \%$ respondents were that inadequate power supply affecting the utilization; and perceptions of $100 \%$ respondents were that accessories did not affect the utilization of radiology and imaging equipments in the district hospitals due to $100 \%$ availability (Table 6).

Table 6: Perception based factors

\begin{tabular}{llll}
\hline Factors & Yes (\%) & No (\%) & Total (\%) \\
\hline Infrastructure & 66.66 & 33.34 & 100 \\
Manpower & 100 & 0 & 100 \\
Working hours & 66.66 & 33.34 & 100 \\
Orientation course & 100 & 0 & 100 \\
Spare parts & 100 & 0 & 100 \\
Maintenance service & 100 & 0 & 100 \\
Work place safety & 66.66 & 33.34 & 100 \\
Accessories & 0 & 100 & 100 \\
Power supply & 33.34 & 66.66 & 100 \\
Others & 66.66 & 33.34 & 100 \\
\hline
\end{tabular}

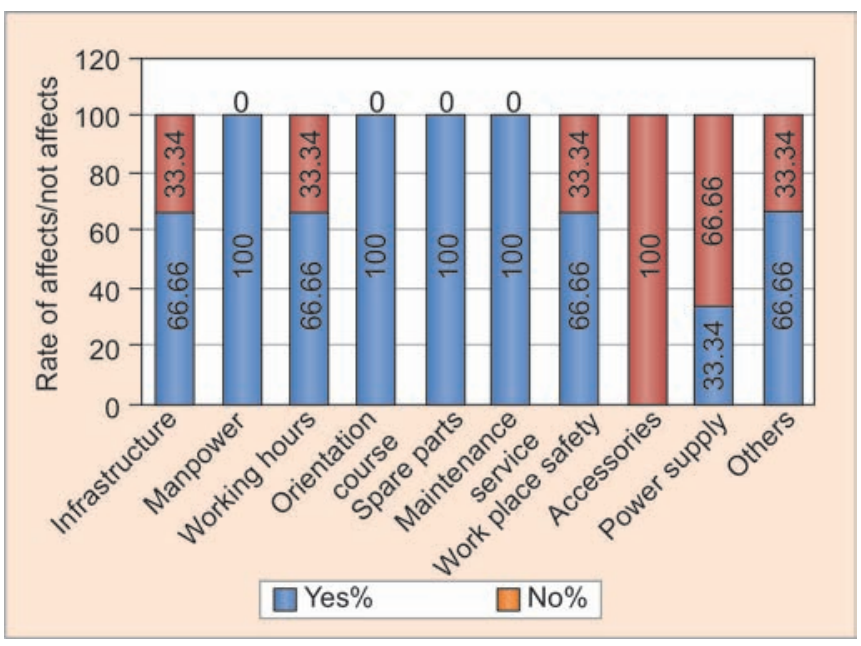

Graph 4: Analysis of perception-based factors affecting the utilization of radiology and imaging equipments

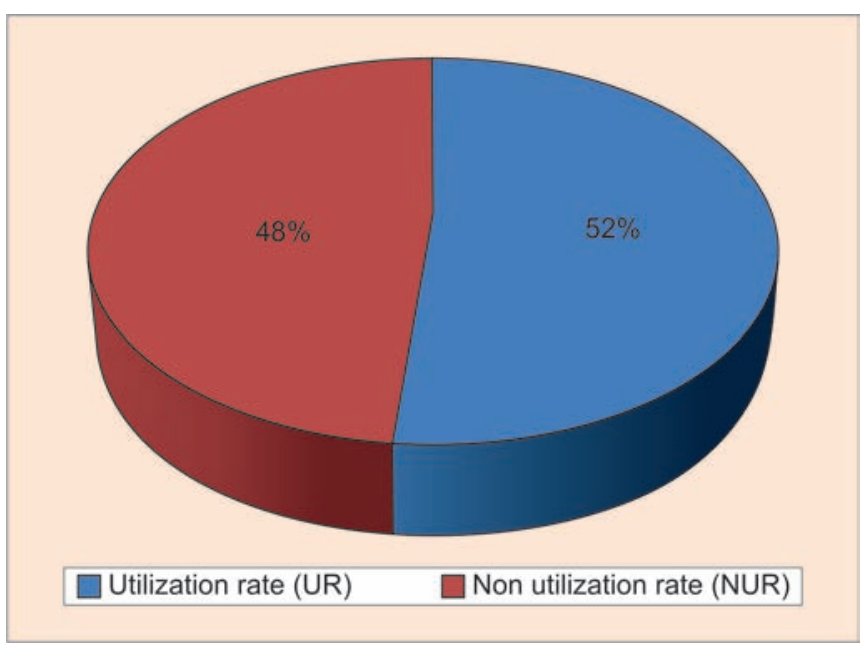

Graph 3: Current status of utilization of radiology and imaging equipments in the district hospitals of Bangladesh

Table 7 shows the distribution of human resources, number of functional radiography, and USG equipments and available physical infrastructure for these equipments. It was observed that, in study area 1, five radiography equipments were installed in one room and manpower was found in one, in study area 2, four radiography equipments were installed in two rooms, but available manpower was also in one, in study area 3, six radiography equipments were installed in a single room and manpower is again one. Two radiography equipments are only utilized and rest of them remain unutilized due to unavailable required room and manpower for each functional equipment.

Graph 5 shows that in study area 1 where computed film processing (CR) system was used and 51 radiology and imaging procedures were carried out/day, total consumed time observed was 344.04 minutes (6 hours and 14 minutes) and time consumed for each procedure was 7.06 minutes; in study area 2 where manual film processing was used and 30 radiological procedures were carried out/day, total consumed time observed was 265.06 minutes ( 4 hours and 41 minutes) and average consumed time for each procedure observed was 8.5 minutes; in study area 3 where manual film processing is used and 39 radiology and imaging procedures carried out/ day, total consumed time observed was 369.10 minutes (6 hours and 15 minutes) and average consumed time for each procedure observed was 9.5 minutes.

Graph 6 shows the number of radiology and imaging procedures carried out during last 5 months. The trend of changing the number of radiology and imaging procedure shows that in General Hospital, Gajipur, the utilization rate of radiology and imaging equipments becomes upward consistently in comparison with other two study areas of General Hospital, Shirajgonj and 250bedded Shadar Hospital, Kishorgonj. While the number 
Table 7: Distribution of human resources, functional equipments, and available physical infrastructure in the three district hospitals

\begin{tabular}{|c|c|c|c|c|c|c|c|c|c|}
\hline \multirow[b]{2}{*}{ Types of work } & \multicolumn{3}{|c|}{ No. of MP } & \multicolumn{3}{|c|}{ No. of FE } & \multicolumn{3}{|c|}{ No. of $A R E$} \\
\hline & $\begin{array}{l}\text { Study } \\
\text { area } 1\end{array}$ & $\begin{array}{l}\text { Study } \\
\text { area } 2\end{array}$ & $\begin{array}{l}\text { Study } \\
\text { area } 3\end{array}$ & $\begin{array}{l}\text { Study } \\
\text { area } 1\end{array}$ & $\begin{array}{l}\text { Study } \\
\text { area } 2\end{array}$ & $\begin{array}{l}\text { Study } \\
\text { area } 3\end{array}$ & $\begin{array}{l}\text { Study } \\
\text { area } 1\end{array}$ & $\begin{array}{l}\text { Study } \\
\text { area } 2\end{array}$ & $\begin{array}{l}\text { Study } \\
\text { area } 3\end{array}$ \\
\hline Radiography & 1 & 1 & 1 & 5 & 4 & 6 & 1 & 2 & 1 \\
\hline USG & 2 & 2 & 2 & 2 & 1 & 1 & 1 & 2 & 1 \\
\hline
\end{tabular}

MP: Manpower, FE: Functional equipment, ARE: Available room for equipment

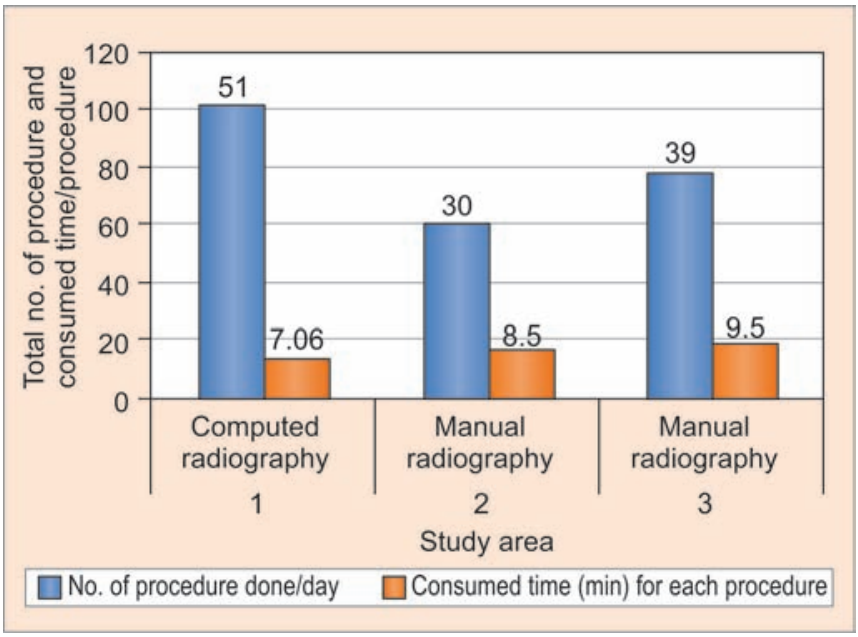

Graph 5: Comparison between efficiency of manual image and computed image procesing method

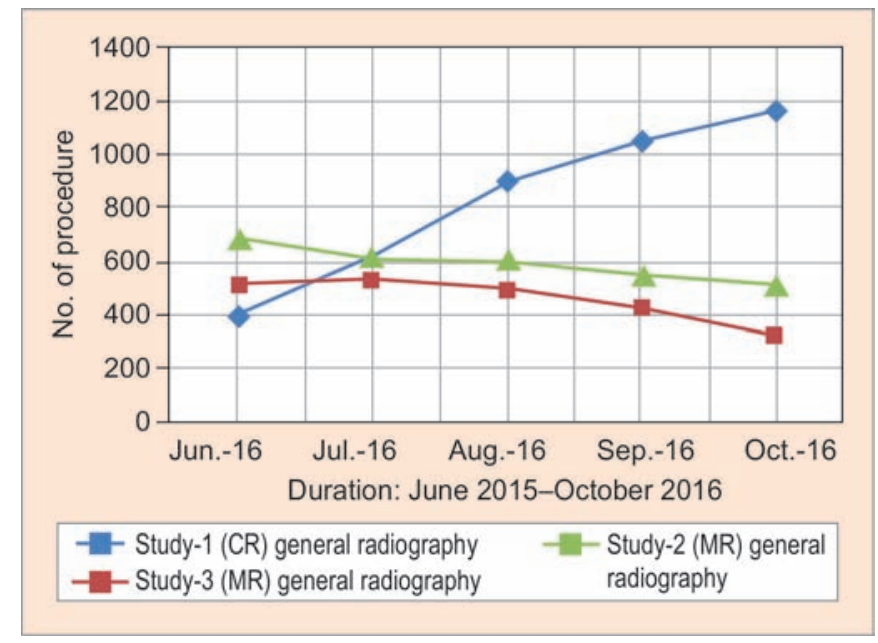

Graph 6: Comparison among the efficiency of radiology and imaging equipments and methods of film processing

According to Bangladesh Medical Equipments Survey Report 2008, 53\% equipments were functional and in use, $12 \%$ functional but not in use, and $35 \%$ were fully nonfunctional. ${ }^{7}$ The current study found $46.9 \%$ radiology and imaging equipments functional, $40.6 \%$ equipments nonfunctional, and $12.5 \%$ equipments functional but not in use in the district hospitals of Bangladesh. Overall $53.1 \%$ radiology and imaging equipments were not utilized. The study also found that $8(25 \%)$ out of 32 equipments became nonfunctional before 10 years. According to American and Canadian standard, minimum lifetime of radiology and imaging equipment is considered 10 years. Life span of greater than 10 years is considered as maximum utilized and lower than 10 years is considered as underutilized. ${ }^{8-10}$ More than $46 \%$ nonfunctional equipments denote the poor maintenance of radiology and imaging equipments. The reasons of nonfunctioning equipments were found to be unavailable spare parts, inadequate fund for spare parts, and unavailable servicing manpower.

The previous study of United States Agency for International Development (USAID) and National Institute of Population Research and Training (NIPORT) found that only $14.5 \%$ equipments are maintained by National Electro Medical Equipments Workshop of Bangladesh. and 29\% equipments are maintained by vendor as per after-sales service warranty up to 1 year of installation, but after completion of the warranty 16 and Microsoft Excel. 
Table 8: Frequency distribution of sociodemographic background of human respondents

\begin{tabular}{|c|c|c|}
\hline & Frequency & Percent \\
\hline \multicolumn{3}{|l|}{ Age } \\
\hline 36-45 years & 3 & 33.34 \\
\hline 46-55 years & 6 & 66.66 \\
\hline Total & 9 & 100 \\
\hline Sex & Frequency & Percent \\
\hline Male & 8 & 88.89 \\
\hline Female & 1 & 11.11 \\
\hline Total & 9 & 100 \\
\hline Marital status & Frequency & Percent \\
\hline Married & 8 & 88.89 \\
\hline Unmarried & 1 & 11.11 \\
\hline Total & 9 & 100 \\
\hline Education & Frequency & Percent \\
\hline Diploma & 3 & 33.34 \\
\hline Postgraduate & 6 & 66.66 \\
\hline Total & 9 & 100 \\
\hline Experience & Frequency & Percent \\
\hline 11-20 years & 3 & 33.34 \\
\hline $21-30$ years & 6 & 66.66 \\
\hline Total & 9 & 100 \\
\hline Income satisfaction & Frequency & Percent \\
\hline Yes & 6 & 66.66 \\
\hline No & 3 & 33.34 \\
\hline Total & 9 & 100 \\
\hline Enough Prof. education & Frequency & Percent \\
\hline Yes & 9 & 100 \\
\hline No & 0 & 0 \\
\hline Total & 9 & 100 \\
\hline Orien. Prog. opportunity & Frequency & Percent \\
\hline Yes & 0 & 0 \\
\hline No & 9 & 100 \\
\hline Total & 9 & 100 \\
\hline
\end{tabular}

period, maintenance services become unavailable due to unavailability of fund as per contract agreement. ${ }^{6}$ According to Bangladesh Medical Equipments Survey Report - April 2008, 5 to 7\% of total capital investment should be reserved for future maintenance services. But this guideline has not been established for some most costly equipments like computed tomography (CT) and magnetic resonance imaging (MRI). The maintenance services are not assured and follow-through life span of radiology and imaging equipments becomes little. ${ }^{7}$

The study measured the actual work time of GR equipment is $67.01 \%$, PR equipment $16.5 \%$, and USG equipments $71.08 \%$. General radiography equipments were idle for $32.99 \%$ time and USG equipments were idle for $28.92 \%$ time out of daily stipulated work time due to interruption of electricity, calibration, personal times of human resources, and unavailability of patients, but PR equipments become idle for $83.5 \%$ time of daily stipulated work time due to unavailability of patients and technologists. According to Principles of Hospital Administration and
Planning by Sakharkar, ${ }_{1}^{11}$ two technologists can carry out maximum 54 radiology and imaging procedures by using one equipment in one room, while daily working time is considered 8 hours; thus one technologist is able to carry out maximum 40 radiology and imaging procedures. This study found one technologist carried out average 39 radiology and imaging procedures during 6.5 stipulated working hours/day by using multiple equipments. It was observed that one technologist was working with GR and PR equipments, so that actual daily work time of technologists was $83.51 \%$, which is quite higher in the district hospitals of Bangladesh.

According to the Bangladesh medical equipments survey report - 2008, the utilization rate was $50.3 \%{ }^{7}$ According to global standards, the utilization rate of radiology and imaging equipments more than $50 \%$ is considered as justified utilization., ${ }^{1,4,10,12}$ The current study found that utilization rate of radiology and imaging equipments is $51.53 \%$ in the district hospitals of Bangladesh, which is significant in comparison with previous study in many developing countries of Asia and Africa along with Bangladesh. But this utilization rate looks still behind in comparison with many developing and developed countries, such as India and the United States. The current ratio of utilization rate of radiology and imaging equipments among Bangladesh, United States, and India is 52\%:53\%:60\%.

According to reported guidelines of Canadian Society of Radiology and Imaging, the average standard of general radiology and imaging procedure/equipment should be at least 15,000 /year, where PR is 4,500 /year and USG is 3,000/year, and equipment should be used at least 8 hours/day. ${ }^{10}$ In Bangladesh, average GR procedure is 7,500/year and number of PR is 1,020 /year, which is underutilized in comparison with international level, and USG is 9,380/year, which is significant in comparison with international standards. Due to short working and accessibility time, service become unavailable for the patients after ending of $6 \frac{1}{2}$ hours daily stipulated working time, so that equipments remains idle for $171 / 2$ hours/day. The utilization of radiology and imaging equipments is just above the minimum standard level. To accelerate the turnover of radiology and imaging equipments, the utilization should be maximized.

According to Nuclear Safety and Radiation Control rules of Bangladesh Atomic Energy Commission and International Atomic Energy Agency, multiple equipments will not be used in a single room at a time under the consideration of radation safety of patient and technlogist. ${ }^{13-15}$ The study found that physical infrastucture was not available in the three district hospitals where multiple equipments were installed in a room, so that while one 
equipment was used, other equipments were idle. The utilization of radiology and imaging equipments was reduced due to inadequte physical infrastucture. This study compared the number of human resources, functional radiography, and USG equipments and available infrastructure for these equipments. In study area 1, five radiography equipments were installed in one room, in study area 2 , four radiography equipments were installed in two rooms, in study area 3, six radiography equipments were installed in a single room. Two radiography equipments were only utilized and rest of them remained unutilized due to shortage of room. According to analysis of perception-based factors affecting the utilization, inadequate infrastructure was most significant.

The study found that shortage of manpower is an important factor that may affect the utilization. The sudy found that one post of medical technologist was available in each 100-bedded district hospitals of Bangladesh, so that more than one equipment was not used at a time. 5,16 While a medical technologist used GR equipment and then portable equipment, dental equipment remained unused; again when he/she used portable equipment, the GR equipment became idle, even 4 (12.50\%) equipments were found functional but not in use in the three hospitals due to shortage of manpower. This study revealed that in study area 1 , functional radiography equipments were found to be five, where manpower was found to be one, in study area 2, functional radiography equipments were found to be four, but available manpower was one, in study area 3, functional radiography equipments were found to be 6 where manpower was one. Only two radiography equipments were utilized and rest of them remained unutilized due to shortage of manpower. According to analysis of perception-based factors affecting the utilization, shortage of manpower was most significant.

Most of the previous studies in India, the United States, and Norway considered rapid technological development as a factor affecting the utilization. ${ }^{1,4,12}$ But the previous studies did not mention how digitization or computerization influences the utilization rate. It was a great effort of the current study to identify how computerized image processing system influences the utilization rate. This study found that while a GR procedure consumes 7.06 minutes by using CR, 8.5 minutes (study area 2) and 9.5 minutes (study area 3 ) is consumed for each procedure by using manual processing system including 25 to 30 minutes drying time. It was observed that, 30 to 45 minutes was required for each manual imaging, while 7-8 minutes was only required for computed method. It was observed that in study area 1 (General Hospital, Gajipur), 51 procedures were carried out by consuming
344.04 minutes with CR, but only 39 procedures were carried out by consuming 369.10 minutes with manual radiography in study area 3 (250 bedded Shadar Hospital, Kishorgonj). The study observed that digitization and computerization influence the utilization of radiology and imaging equipments in the district hospitals of Bangladesh.

The study observed that most of the sociodemographic background of respondents was not corelated with utilization of radiology and imaging equipments in the district hospitals of Bangladesh. The respondents were experienced, professionally qualified, and satisfied with their income. The sociodemographic background, such as age, sex, marital status, income, and experience of all respondents were significant, which may positively influence the utilization rate. This study observed that all respondents are professionally educated but they have no adequate opportunity for orientation program or newer technologies. Different studies in India, United States, Norway, and Ethiopia found that less skilled operating manpower is the key factor affecting the utilization rate of newer modalities. ${ }^{1,3,4,12}$ Bangladesh Health Facility Survey Report 2014 revealed that human resources development program was available for only $13 \%$ of workforce who are working with high technology, such as CT and MRI. The study of USAID and NIPORT noted that although 7\% of total cost of the equipments is mandatory for human resources development, it was not maintained, ${ }^{6}$ so that most of the sophisticated equipments are being operated without adequate knowledge and skills.

\section{CONCLUSION}

A study was conducted in the radiology department of three district hospitals based on daily $6 \frac{1}{2}$ hours stipulated working time to identify the functional status, workload, utilization, and factors affecting the utilization of radiology and imaging equipments. According to the study results, a significant number (53\%) of radiology and imaging equipments in the district hospitals were nonfunctional and functional but not in use. It was found that more than $50 \%$ capital investments remained unused in the district hospitals, which reduced the turnover of radiology and imaging equipments. Average daily work time of GR equipments was found to be $67.01 \%$, PR equipments $16.5 \%$ and USG equipments $78.08 \%$. Actual work time of radiologists was $71.08 \%$ and technologist $83.51 \%$. Average utilization rate of radiology and imaging equipments in the district hospitals was identified as 51.53\%, which was more than the standard (50\%) and was significant in comparison with many developing countries of Southeast Asia and Africa. The current utilization rate needs to accelerate to increase the turnover of radiology 
and imaging equipments in the district hospitals of Bangladesh. Adequate human resources, physical infrastructure, as well as incorporating advanced technology with existing facility may be considered for more utilization of radiology and imaging equipments. Three district hospitals were not enough to generalize 61 district hospitals. A wide range of studies may be considered for more extensive result. Perception-based factors of respondents may also be considered for further evaluation to find out how they influence the utilization rate.

\section{ACKNOWLEDGMENTS}

Authors would like to convey his gratitude to the respective faculty members of State University of Bangladesh for their valuable support to carry out the research. The authors would also like to acknowledge the unconditional support of radiologists and medical technologists of General Hospital, Gajipur, General Hospital, Shirajgonj, and 250-bedded General Hospital, Kishorgonj, for their effective cooperation to provide relevant documents, information, and valuable time to collect data among the hospitals.

\section{REFERENCES}

1. Poonam C, Pankaj K. Factors affecting the utilization of medical diagnostic equipment: a study at a tertiary healthcare setup of Chandigarh. CHRISMED J Health Res 2015:2(4): 216-223.

2. European Society of Radiology. Renewal of radiological equipments. Insights Imaging 2014 Oct;5(5):543-546.

3. Adme BW, Tabeje B, Molla A. Availability and utilization of medical devices in Jimma zone hospitals. Southwest Ethiopia: a case study. Ethiopia: Biomed Central; 2016. Available from: http//creativecommons.org.

4. Lysdall KB. Utilization and utility of diagnostic imaging. Vol. 1253. Oslo, Norway; 2012.

5. WHO, MOHFW. Human Resources for Health: Country Profile of Bangladesh, Bangladesh; 2013 Aug.

6. USAID, NIPORT. Bangladesh Health Facility Survey Report; 2014. p. 36-37. Available from: http://www.dghs.bd.

7. SIMED International. Bangladesh Medical Equipment Survey Report; 2008 Apr. p. 26-48.

8. RBMA. Imaging Equipment Utilization Rates in America; 2009. p. 5-6. Available from: https://www.rbma.org.

9. David M, John K, Stephen M. Maintenance and management of equipments in hospital. Ind Eng Lett 2012;2(3):9-19.

10. Canadian Association of Radiologists. Life Cycle guidance for Medical Imaging Equipments for Canada; 2013.

11. Sakharkar BM. Principles of hospital administration and planning. 2 ed. India; 2009. p. 191.

12. Bhargavan M1, Sunshine JH. Utilization of radiology services in the United States: levels and trends in modalities, regions and populations. Radiology 2005 Mar;234(3):824-832.

13. Haider M, Begum L, Amiree RA. Shielding analysis for conventional X-ray machine install at district towns in Bangladesh. Am Int J Res Sci Technol Eng Math 2015;15(29).

14. Begum Z. Present status of quality assurance in diagnostic radiology in Bangladesh. In: Long $\mathrm{M}$, editor. World Congress on Medical Physics and Biomedical Engineering May 26-31, 2012, Beijing, China. IFMBE Proceedings, Vol. 39. Berlin, Heidelberg: Springer; 2013. p. 1045-1048.

15. IAEA. Safety Report Series. Applying Radiation Safety Assurance in Radiology. Vienna; 2006 Oct:(39). Available from: http://www-ns.iaea.org/standards/.

16. Roshni FS, Zahid A, Daniel G, Hussain Z, Germoni F, Hossain AM. Standardization of medical equipments organizational structure and equipment planning. Dhaka: USAID and SIAPS; 2016 Apr. 